\title{
Technical difficulty in component sizing and positioning in humeral resurfacing: Relationship to clinical outcomes
}

\author{
P Ryan MBChB (UCT), FC(Orth) (SA), MMed(Orth) UKZN \\ Department of Orthopaedic Surgery, University of KwaZulu-Natal \\ Dr C Anley MBChB, FC(Orth)SA \\ Dr A Lambrechts MBChB, MMed(Orth)Pret \\ Dr B Vrettos MBChB(Zim), FRCS(Eng), FCS(SA)Orth, MMed(Orth)UCT \\ Dr S Roche MBChB(UCT), LMMC, FCS(SA)Orth \\ Department of Orthopaedic Surgery, University of Cape Town \\ Corresponding author: \\ Dr P Ryan \\ Email: paullisa.ryan@gmail.com
}

\begin{abstract}
Introduction: Resurfacing of the glenohumeral joint has gained popularity since its first introduction. Among other advantages, it is reported to allow closer replication of individual anatomy - failure of which may produce inferior clinical results. We review a cohort of patients who had undergone proximal humeral resurfacing, to evaluate certain radiological parameters of component sizing and positioning, and to correlate these with the clinical outcomes.
\end{abstract}

Materials and methods: From January 2000 to March 2011, 51 humeral resurfacing procedures were performed in 49 patients. Patients were contacted for review, and assessed using patient-reported outcome measures. An Oxford Shoulder Score (OSS) as well as a subjective satisfaction and outcome questionnaire were completed, as well as details regarding further surgery or revision. Radiographs were evaluated for component size, offset, inclination and height. Two patients had demised, ten patients were not contactable, and in four the medical files had been lost. In the remaining 35 shoulders, the average follow-up was 5.43 years. The mean age at time of surgery was 64.8 years (range 36 to 84 ).

Results: Complications included eight revisions (average 2.4 years post-surgery), while a further one patient awaits revision. The mean OSS in the unrevised shoulders was 36.1 (range 10 to 48). There was no difference between the revised and unrevised group for peri-operative variables (pre-op diagnosis, smoking status, age, gender, surgeon involved), or any of the radiographic variables (inclination, offset, prosthesis height, increase in head size). In the unrevised group, there was no correlation between the OSS and radiographic measurements of offset, inclination or head height. Prostheses that subjectively appeared mal-sized or mal-positioned obtained better OSSs and subjective satisfaction scores. Revised cases were all subjectively satisfied post revision to stemmed total shoulder replacement.

Conclusion: We have demonstrated difficulties in correct sizing and component placement as evident by the post-operative radiographic analysis, but are unable to correlate these with clinical scores. We have encountered a wide range of patient-reported shoulder scores and levels of satisfaction which, however unexplainably, have shown better scores for subjectively mal-sized and mal-positioned prostheses.

Key words: humeral resurfacing, shoulder replacement, shoulder arthroplasty 


\section{Introduction}

The shoulder is the third most common large joint that requires surgical reconstruction. The number of arthroplasty cases, both hemi and total joint replacement, is also increasing, with around 47000 cases performed in the United States in 2008. ${ }^{1}$ The surgical decision is based in part on patient factors such as age, comorbidities, activity requirements, rotator cuff integrity, and bony anatomy.

There are a number of advantages of resurfacing compared to conventional stemmed arthroplasty, including an easier replication of proximal humeral anatomy. ${ }^{2.3}$ However, a few studies highlight the technical difficulties during prosthesis insertion, and the problems with adequately restoring the prosthesis inclination, offset and version. ${ }^{4-7}$ Subsequent mal-sizing or mal-positioning may produce inferior clinical outcomes. ${ }^{2,7}$

With this in mind, we set out to review a cohort of patients who had undergone proximal humeral resurfacing, to evaluate certain radiological parameters of component sizing and positioning, and to correlate these with their clinical outcomes.

\section{Materials and methods}

We reviewed a group of patients with arthrosis of the glenohumeral joint who underwent humeral resurfacing, and who were at a minimum of two years post-surgery. From January 2000 to March 2011, 51 humeral resurfacing procedures were performed in 49 patients by three shoulder surgeons (AL, SR, BV). The indication for surgery was severe pain, unresponsive to non-surgical management.

Patients' charts were canvassed for demographic, surgical and post-operative data.

At time of review, two patients had died, ten patients were not contactable, and in four the medical files had been lost. In the remaining 35 shoulders, the average follow-up was 5.43 years (2-10.5 years), and the mean age at time of surgery was 64.8 years (range 36 to 84 ). There were 15 males (mean age 60.9 years) and 20 females (mean age 67.7 years).

Patients were contacted for review, and assessed using patient-reported outcome measures (PROMs). An OSS (a PROM with a maximum attainable score of 48 and divided into groups: $0-19$ severe arthritis; $20-29$ moderate to severe; $30-39$ mild to moderate; $40-48$ satisfactory $)^{8}$ as well as a subjective satisfaction and outcome questionnaire was completed. Details regarding further surgery or revision were asked for.

The pre-operative diagnosis was primary osteoarthritis $(\mathrm{OA})$ in 28, rheumatoid arthritis (RA) in three, previous fracture in two, avascular necrosis (AVN) in one, and cuff tear arthropathy (CTA) in one.

The surgery was performed through a delto-pectoral approach in 33 and via an antero-superior approach as described by Neviaser and Neviaser, ${ }^{9}$ and MacKenzie ${ }^{10}$ in two.
The subscapularis tendon was tenotomised in all cases and tagged for later repair. Capsular release was performed as necessary, and the glenoid inspected. Additional procedures were performed as follows: biceps tenotomy in nine, biceps tenodesis in two, acromioplasty in six, acromioclavicular joint excision in four, and repair of small cuff tears in two. In two cases drilling of the glenoid was performed, and in one glenoplasty was performed, a socalled 'ream and run' technique as described by Matsen. ${ }^{11}$ The prostheses used were the Copeland Surface Replacement Arthroplasty in five and the Global Cap in 30. The prostheses were cemented in five cases, and the rest were uncemented press fit.

Radiographs were evaluated for the following measurements: pre-operative head size and offset (Figure 1), postoperative head size, offset (Figure 2), inclination and prosthesis height above the greater tuberosity (Figure 3). The offset refers to the distance from the lateral aspect of the greater tuberosity to the centre of rotation of the humeral head.

Post-operative radiographs were then subjectively evaluated by two surgeons, blinded to the clinical outcomes. Head size was graded as undersized, good, or oversized. Prosthesis placement was graded as optimal or suboptimal, and if suboptimal was graded as medialised, or lateralised, malaligned in varus or valgus, or a combination. Overall appearance of the humeral component and its positioning was then graded as being optimal, acceptable or suboptimal.

We evaluated certain radiological parameters of component sizing and positioning, and correlated these with their clinical outcomes

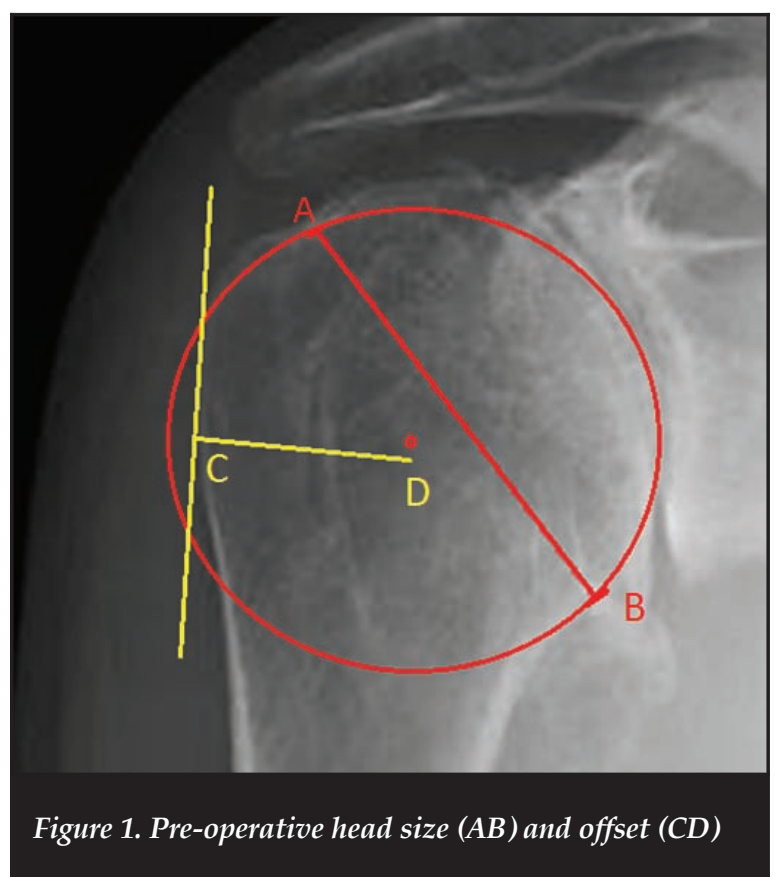




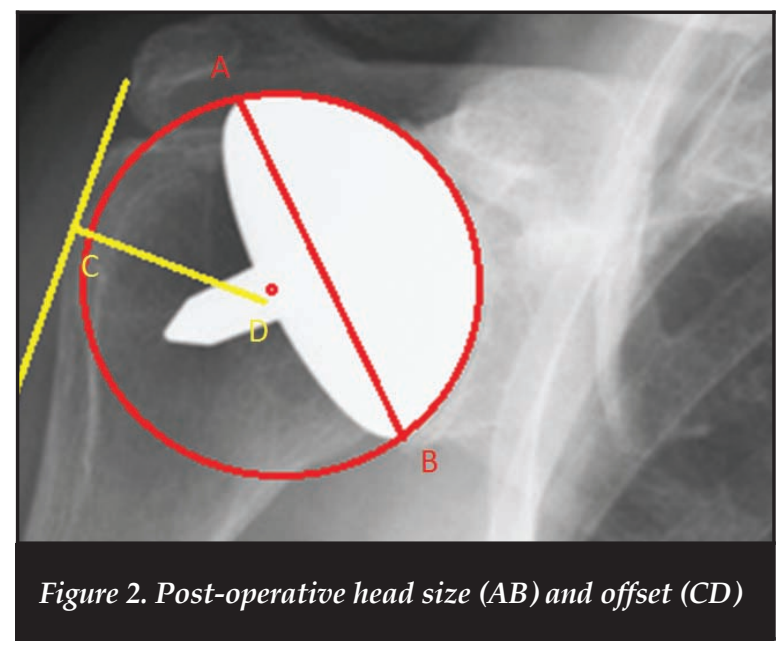

\section{Results}

A total of 35 patients was reviewed. Eight patients (22.9\%) had undergone revision to stemmed total shoulder arthroplasty (TSA) (Table I), and one awaits revision. The mean time to revision was 30.75 months (range 8-48), and the indication was either continued pain post resurfacing, or the re-occurrence of pain. Three of these patients had

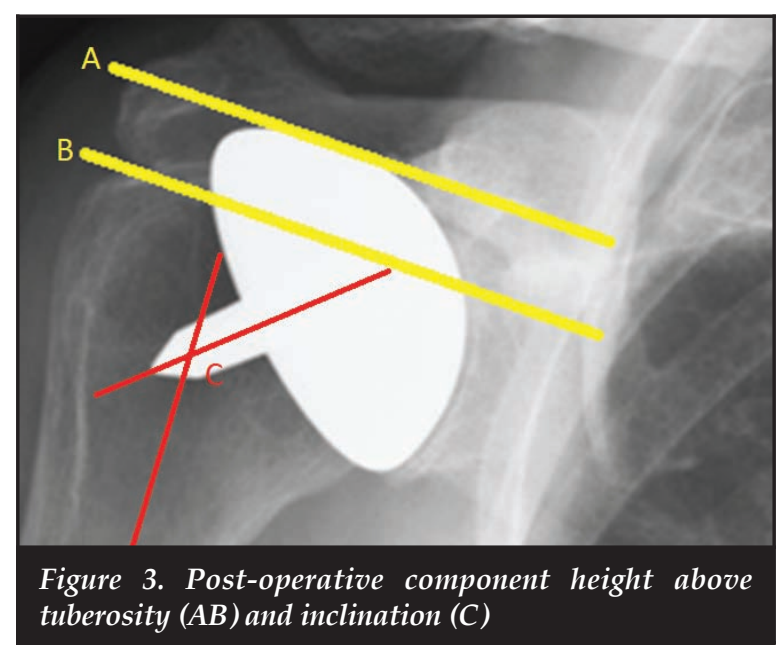

undergone further surgery prior to revision to TSA: repair of the subscapularis tendon in one, arthroscopic acromioplasty and subacromial decompression in one, and acromioplasty and acromio-clavicular joint excision in one. All were subjectively satisfied with their shoulders post revision surgery.

\begin{tabular}{|c|c|c|c|c|c|c|c|c|c|c|}
\hline Case & $\begin{array}{l}\text { Age } \\
(y r)\end{array}$ & Gender & $\begin{array}{c}\text { Pre-operative } \\
\text { diagnosis }\end{array}$ & $\begin{array}{l}\text { Pre-op range } \\
\text { of movement } \\
\text { Flex, Abd, ER }\end{array}$ & $\begin{array}{c}\text { Co- } \\
\text { morbidities }\end{array}$ & Surgeon & $\begin{array}{l}\text { Time to } \\
\text { revision } \\
\text { (months) }\end{array}$ & $\begin{array}{l}\text { Indication } \\
\text { for } \\
\text { revision }\end{array}$ & $\begin{array}{c}\text { Revision } \\
\text { surgery }\end{array}$ & Notes \\
\hline 1 & 55 & F & $\begin{array}{l}\text { Previous } \\
\text { fracture }\end{array}$ & $90 / 70 /-10$ & HPT & C & 40 & $\begin{array}{l}\text { Pain/ } \\
\text { glenoid } \\
\text { erosion }\end{array}$ & TSA & $\begin{array}{l}\text { Tuberosity } \\
\text { malunion, } \\
\text { previous scope, } \\
\text { stiff shoulder }\end{array}$ \\
\hline 2 & 60 & $\mathrm{~F}$ & OA & & Nil & B & 51 & Pain & TSA & \\
\hline 3 & 74 & M & OA & $170 / 95 / 45$ & $\begin{array}{l}\text { IHD, HPT, } \\
\text { cholesterol }\end{array}$ & A & 8 & Pain & & $\begin{array}{l}\text { Subscapularis } \\
\text { repair } 3 \text { months } \\
\text { after index } \\
\text { surgery }\end{array}$ \\
\hline 4 & 60 & $\mathrm{~F}$ & OA & $140 / 95 / 60$ & Nil & A & 48 & Pain & TSA & \\
\hline 5 & 68 & F & OA & $100 / 60 / 20$ & $\begin{array}{l}\text { HPT, } \\
\text { NIDDM, } \\
\text { PUD }\end{array}$ & C & 12 & Pain & TSA & \\
\hline 6 & 71 & F & OA & $130 / 80 / 30$ & $\begin{array}{l}\text { IHD, HPT, } \\
\text { CCF, } \\
\text { asthma }\end{array}$ & A & 24 & Pain & TSA & \\
\hline 7 & 75 & F & OA & $130 / 85 / 30$ & $\begin{array}{l}\text { HPT, } \\
\text { asthma }\end{array}$ & A & 15 & Pain & TSA & $\begin{array}{l}\text { Acromioplasty } \\
11 \text { months after } \\
\text { index surgery }\end{array}$ \\
\hline 8 & 63 & F & OA & $130 / 90 / 0$ & $\begin{array}{l}\text { NIDDM, } \\
\text { PUD, HPT }\end{array}$ & C & 48 & Pain & TSA & $\begin{array}{l}\text { Acromioplasty } \\
\text { and AC joint } \\
\text { excision } \\
14 \text { months after } \\
\text { index surgery }\end{array}$ \\
\hline
\end{tabular}


Of the remaining 27, the mean Oxford Shoulder Score (OSS) was 36.1 (range 10-48). Seventeen patients reported being either very satisfied or satisfied, seven were unsure, and three were either unsatisfied or very unsatisfied with their resurfacing procedure. Twenty-one said they were either much better or better than prior to surgery, four were unsure, and two were either worse or much worse than prior to surgery. Twenty-two patients would be willing to undergo the procedure were they able to make the decision again, two were unsure, and three would not.

Two patients had undergone further surgical procedures, a biceps tenotomy in one, and transfer of the pectoralis major tendon for an irreparable subscapularis rupture in one.

Radiologically, the pre-operative head size increased from a mean of $45.7 \mathrm{~mm}$ to $48 \mathrm{~mm}$ post-operative; and the preoperative offset increased from a mean of $25.2 \mathrm{~mm}$ to $29 \mathrm{~mm}$. The inclination averaged $143^{\circ}$ (range $118^{\circ}-162^{\circ}$ ); and the head height above the greater tuberosity averaged $9.6 \mathrm{~mm}$ (range 3-15 mm). Subjectively, the head size was graded as undersized in 5\%, well sized in $62 \%$, and oversized in $33 \%$. The cap position was graded as optimal in $35 \%$ and suboptimal in $65 \%$. With regard to overall appearance of the prostheses, $17 \%$ were graded as optimal, $12 \%$ as acceptable, and $71 \%$ as suboptimal, highlighting the surgeons' difficulties with both sizing and positioning.

We analysed the above data to establish any causal relationship between pre-operative factors, surgical factors and post-operative component analysis, with postoperative scores, satisfaction levels and the need for revision.

With regard to revision, the rates for surgeons were: A $25 \%$, B $12.5 \%$, C $27.3 \%$; however, we could not establish statistical significance between individual surgeons. Revision rates between the two prostheses were not significant, with one of five $(20 \%)$ Copeland prostheses and seven of $30(23 \%)$ Global Cap prostheses revised. There was no relationship between gender $(p=0.419)$, smoking status $(\mathrm{p}=0.532)$, age at surgery $(\mathrm{p}=0.954)$ or pre-operative diagnosis $(\mathrm{p}=0.653)$ with revision.

With regard to the radiographic parameters in the revision group, the average head size increased by $3 \mathrm{~mm}$, the average post-operative inclination was $140^{\circ}$, the average offset was $27.5 \mathrm{~mm}$, and the head height was $11.75 \mathrm{~mm}$. These readings were all similar to those for the unrevised group, but as a number of either the pre- or post-operative $\mathrm{X}$-rays were unobtainable, we were not able to evaluate statistical significance.

In the unrevised cases, we could not find any difference in the median OSS or satisfaction between surgeons $(\mathrm{p}=0.483)$. There was no correlation between age and OSS (correlation coefficient -0.155 ), age and satisfaction $(-0.107)$, gender and OSS $(p=0.408)$, gender and satisfaction $(\mathrm{p}=0.304)$, smoking status and OSS $(\mathrm{p}=0.698)$, smoking status and satisfaction $(\mathrm{p}=0.548)$.

There was a weak negative correlation between the number of comorbidities and satisfaction scores (Graph 1).
There was no significant difference in OSS between the diagnoses ( $p=0.196)$; however, there was a difference in satisfaction scores between diagnoses (Graph 2). This should be interpreted with caution because of small numbers in the groups other than OA.

We found no difference in results of surgeries performed early in the series compared to those done more recently (OSS $\mathrm{p}=0.157$ and satisfaction $\mathrm{p}=0.157$ ).

In this series, the median OSS for the Copeland was 46, and for the Global Cap $39(\mathrm{p}=0.045)$, but again this should be interpreted with caution because of small numbers of Copeland prostheses inserted.

We evaluated certain radiographic parameters to see if they corresponded to outcomes. Neither head height (Spearman's correlation coefficient 0.071$)$, offset $(-0.014)$ nor inclination (0.134) correlated to subjective scores.

On subjective evaluation of prosthesis size and position, those that appeared oversized or undersized had better OSS than those that were rated as of optimal size (Graph 3), and this correlated with the satisfaction score (Graph 4). There was also a correlation between whether the cap had been inserted in a subjectively optimal, satisfactory or suboptimal position (median OSS 19, 44, 41.5 respectively, $\mathrm{p}=0.040$ ), with those inserted in unsatisfactory position obtaining better OSS and subjective satisfaction levels (Graphs 5 and 6).

There was a statistical significance between surgeons for inclination angle $(\mathrm{p}=0.04)($ Graph 7$)$, but inclination angle did not correlate with clinical outcome. Head height and offset were not evaluated between surgeons, as these did not influence clinical outcomes in this series.

Neither head height (Spearman's correlation coefficient 0.071), offset (-0.014) nor inclination (0.134) correlated to subjective scores

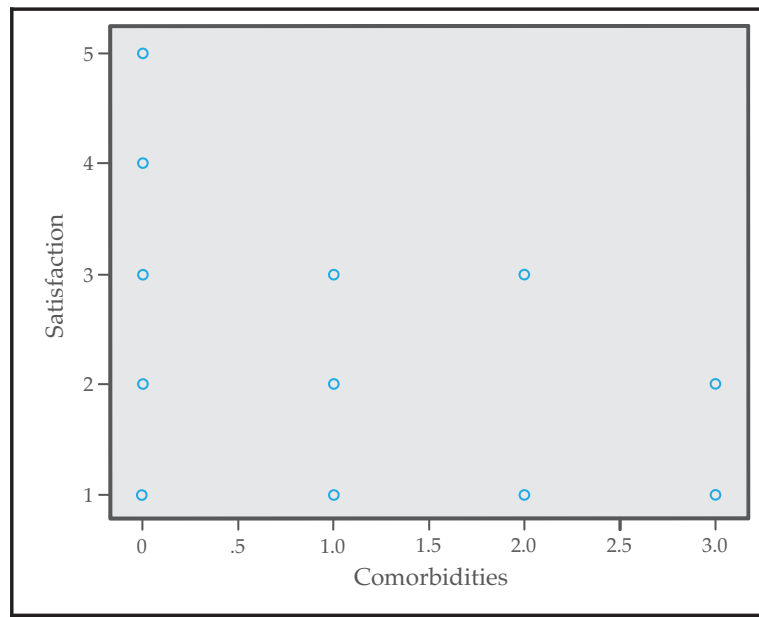

Graph 1. Relationship between number of comorbidities and satisfaction score 


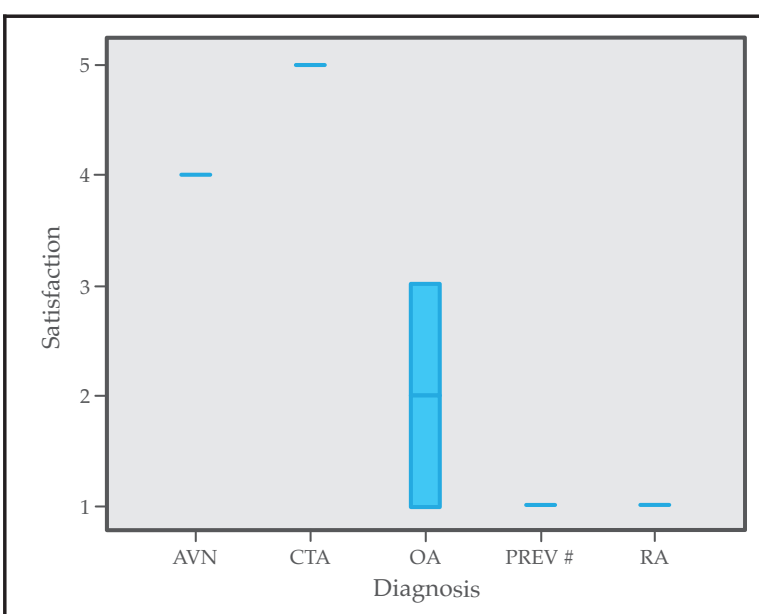

Graph 2. Relationship between underlying diagnosis and satisfaction

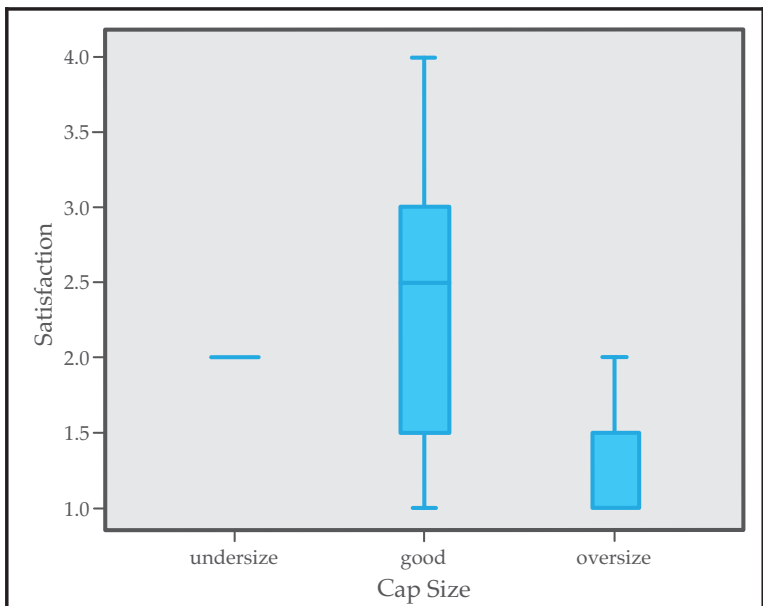

Graph 4. Relationship between subjective component size and satisfaction

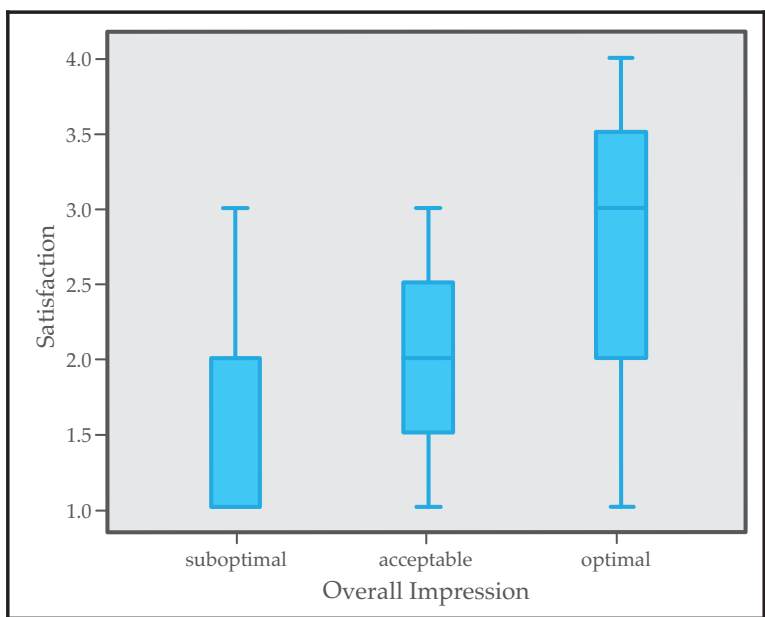

Graph 6. Subjective component position and satisfaction

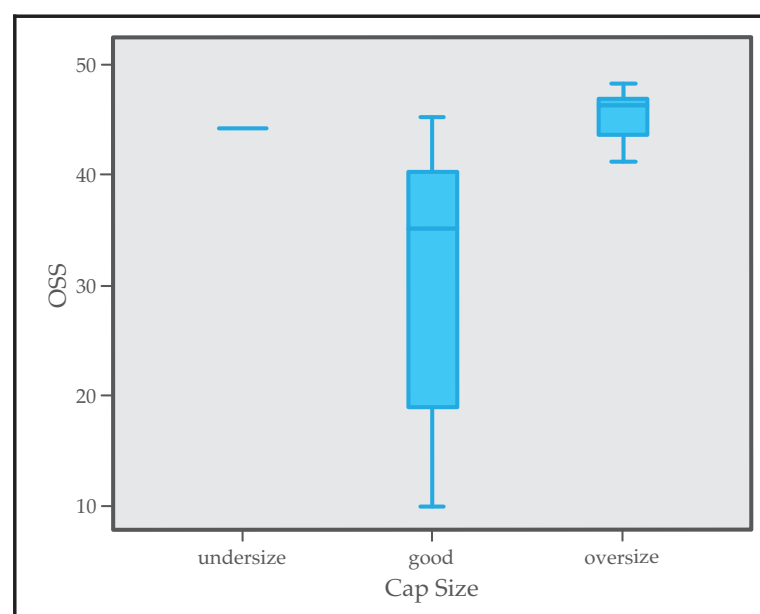

Graph 3. Relationship between subjective component size and OSS

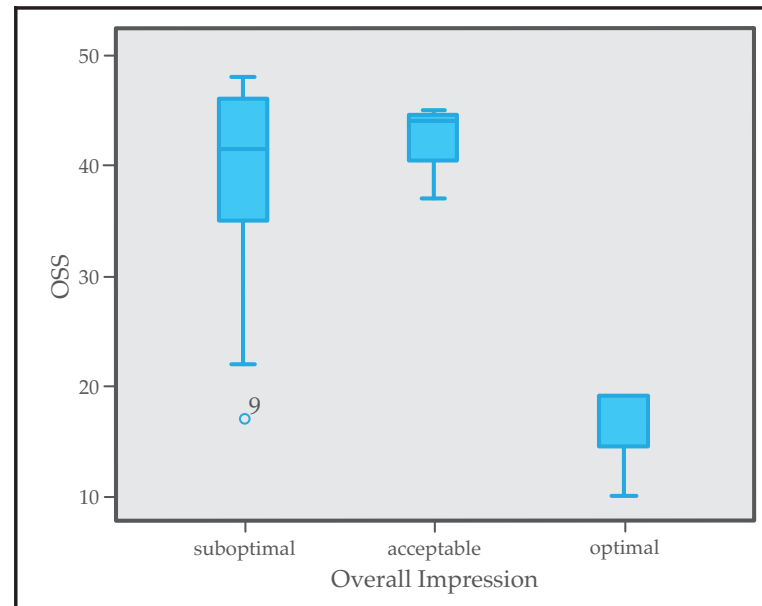

Graph 5. Subjective component position relation with Oxford Shoulder Score

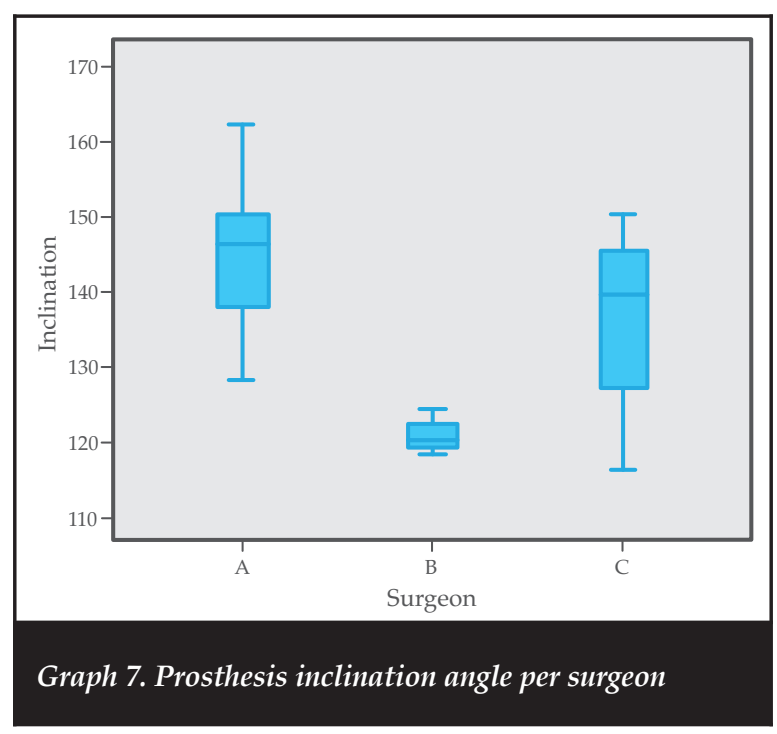




\section{Discussion}

The reported advantages of surface replacement over stemmed components include: easier replication of patient's anatomy, reduced risk of intra-operative periprosthetic humeral fracture and stem perforation, preservation of humeral bone stock, and relative ease in revision to a stemmed component if needed. . $3,12-14^{-14}$

Surface replacement is also suggested to be more practical in cases of proximal humeral deformity secondary to fracture mal-union. In such cases, insertion of a stemmed component may not be possible, or may require adjunctive humeral osteotomy. Humeral perforation and / or fracture pose a significant risk, and humeral resurfacing may afford a more practical solution. ${ }^{15,16}$ Humeral resurfacing compared to standard stemmed total shoulder arthroplasty (TSA) may also have socioeconomic implications, with resurfacing hemiarthroplasty needing shorter operative time, and shorter periods of inpatient treatment. ${ }^{13}$ Resurfacing is also considered to be a safer procedure in the elderly population as there is minimal blood loss, and it avoids intramedullary reaming and cementation with their possible anaesthetic and medical complications. ${ }^{14}$

Published results of resurfacing procedures have shown similar clinical outcomes to those of stemmed implants.,

In this study, there were no cases of intra-operative humeral fractures, and no peri-operative ischaemic events to suggest excessive blood loss. Although we did not analyse operative time, post-operative haematological studies (in order to gauge blood loss), or hospital stay, anecdotally the authors agree with the published literature regarding the suitability of resurfacing in helping to optimise these parameters.

At a mean of 5.4 years follow-up, eight of the 35 $(22.8 \%)$ resurfacings have been revised, and one awaits revision. The indication for revision in all was pain and glenoid wear. With regards to the revision surgeries, there were no cases of humeral fracture (as may be seen in revision of stemmed components), no excessive blood loss recorded, and no note of gross difficulties or prolonged surgery. As reported, all underwent revision to a stemmed TSR, and are subjectively happy with the outcome of revision.

We were unable to clearly demonstrate an association with the revision cases and any of the pre-operative and operative factors, or the post-operative radiological analysis, when compared to the unrevised cases.

In the published literature, the revision rate for resurfacing arthroplasty varies substantially, and within series it differs for the underlying diagnoses (Table II).

Thomas et al. ${ }^{2}$ prospectively evaluated 39 resurfacings (32 hemi and seven total shoulder). At a mean of 38 months (24-72), the adjusted Constant score (CS maximum score 100$)^{17}$ had increased to 84 for the hemi group and 83 for the TSA group. There is no mention of any revisions in the series.

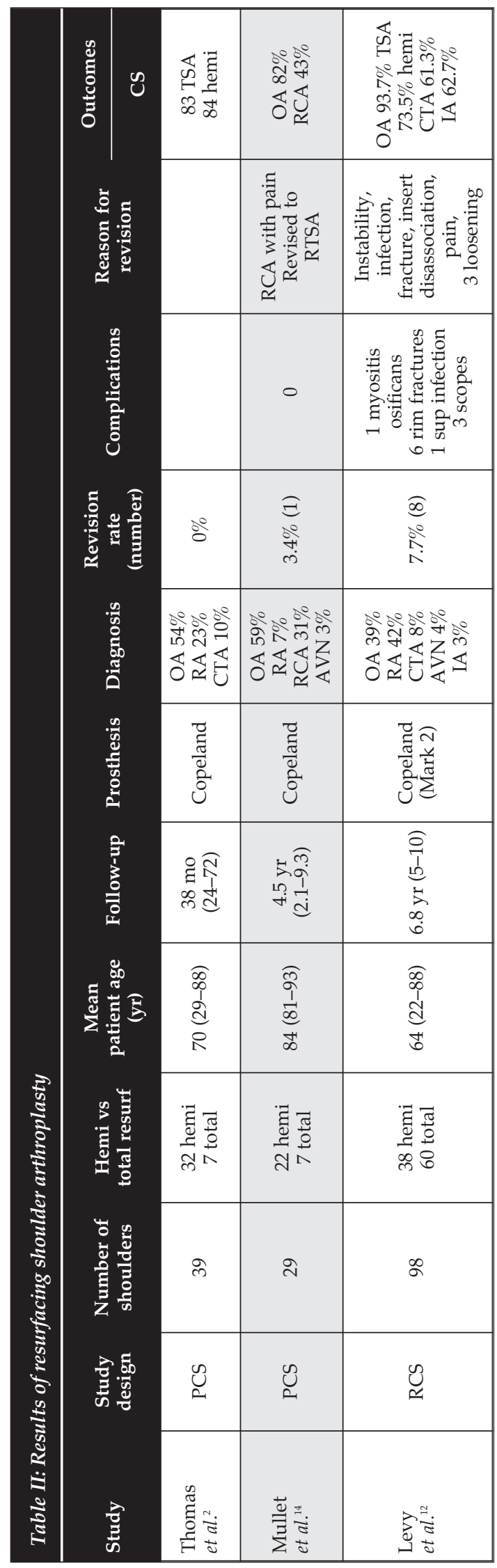




\begin{tabular}{|c|c|c|c|c|c|c|c|c|c|}
\hline O & & 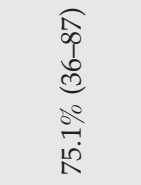 & 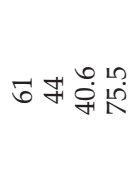 & 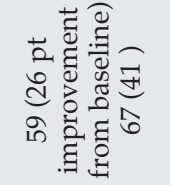 & 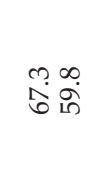 & $\begin{array}{c}\text { Di } \\
\infty \\
\infty\end{array}$ & 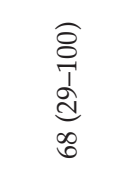 & & 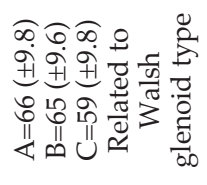 \\
\hline के & $\begin{array}{l}\infty \\
D^{\infty} \\
\stackrel{\infty}{=} \\
\not{7}\end{array}$ & 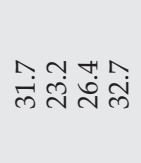 & & & & & 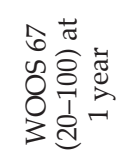 & & \\
\hline 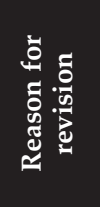 & 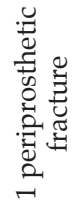 & & 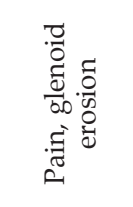 & 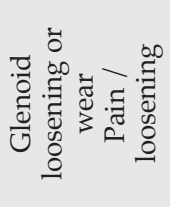 & & & 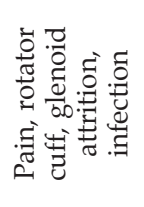 & 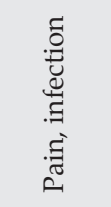 & \\
\hline 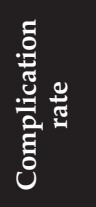 & $\frac{i}{\lambda}$ & & & & & 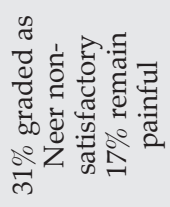 & & & 0 \\
\hline 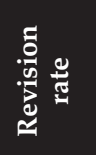 & 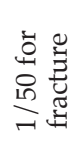 & 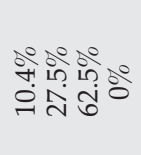 & s̊ & 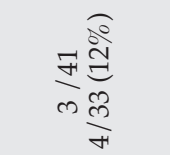 & 0 & $\frac{8}{\infty}$ & 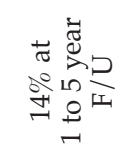 & 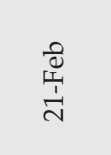 & \\
\hline 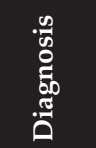 & 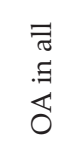 & 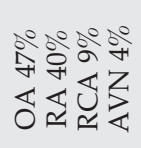 & லீઠ & 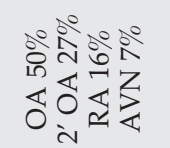 & 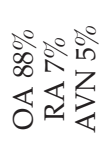 & 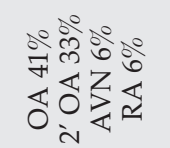 & 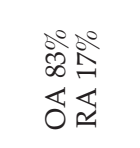 & 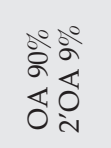 & 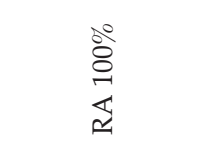 \\
\hline 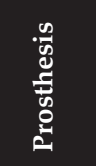 & 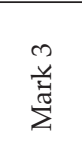 & 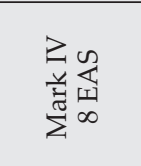 & 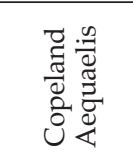 & 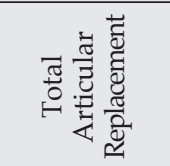 & 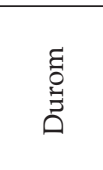 & $\begin{array}{l}\text { 㐫 } \\
\frac{\pi}{\pi} \\
\frac{0}{0} \\
0\end{array}$ & 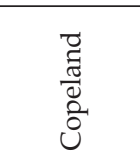 & 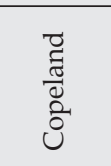 & 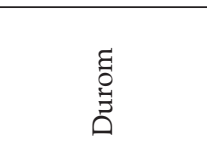 \\
\hline $\begin{array}{l}\frac{7}{7} \\
0 \\
0 \\
0\end{array}$ & \begin{tabular}{l}
$\widehat{0}$ \\
$d$ \\
$d$ \\
5 \\
\multirow{1}{7}{}
\end{tabular} & 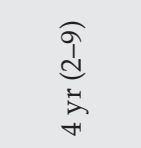 & 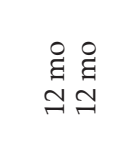 & 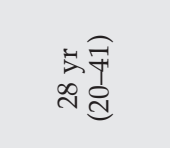 & 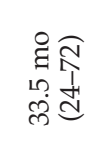 & 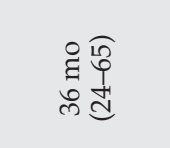 & 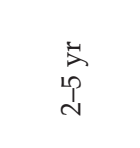 & $\begin{array}{rl} & 0 \\
50 & 0 \\
0 & 0 \\
+ & 1 \\
+ & d\end{array}$ & 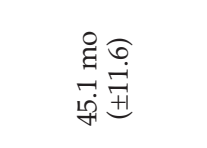 \\
\hline 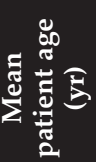 & 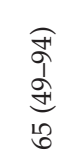 & $\begin{array}{l}\overparen{a} \\
\vdots \\
2 \\
2 \\
0 \\
0 \\
0\end{array}$ & تُ & $\begin{array}{l}\overparen{1} \\
\mathcal{1} \\
\text { d్ } \\
\infty \\
i n\end{array}$ & 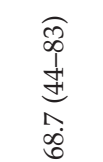 & $\begin{array}{l}\text { के } \\
0 \\
0 \\
0 \\
\text { î } \\
\text { in }\end{array}$ & 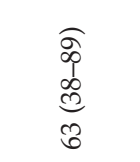 & $\begin{array}{l}\text { ô } \\
0 \\
1 \\
0 \\
0 \\
0 \\
\infty \\
1 \\
10\end{array}$ & 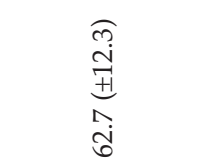 \\
\hline 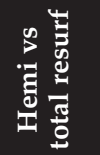 & 苞 & 节 & 泀焉 & 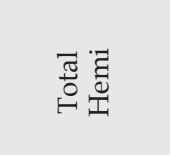 & 苞 & 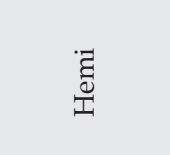 & 苞 & 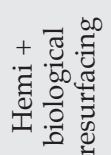 & 苞 \\
\hline 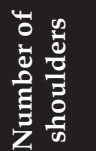 & in & ऽ̊ & 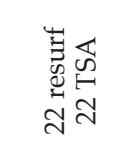 & $F \ddot{m}$ & 7 & ठే & $\Sigma$ & $\bar{N}$ & 导 \\
\hline 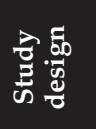 & $\underset{\mathscr{y}}{\mathscr{y}}$ & 岁 & 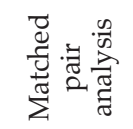 & y & $\tilde{y}$ & y & $\mathscr{U}$ & $\tilde{y}$ & U \\
\hline 롤 & 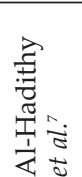 & 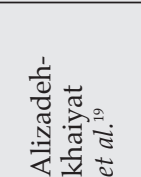 & 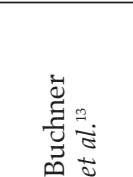 & 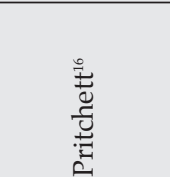 & 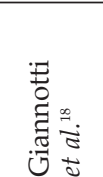 & 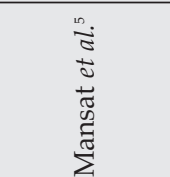 & 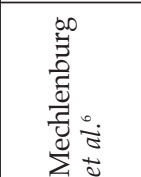 & 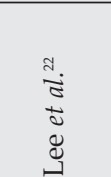 & 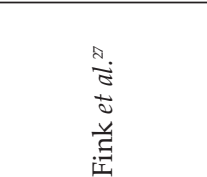 \\
\hline
\end{tabular}


Giannotti et al ${ }^{18}$ evaluated 42 consecutive hemi resurfacings. There were no revisions, and at a mean followup of 33 months, they report a mean improvement in CS of almost 30 points to a mean score of 82.34. They highlight that a morphologically and functionally normal rotator cuff is a crucial prerequisite to this type of surgery, which can be performed as a hemi-resurfacing in type A and B1 glenoids.

Mullet et al..$^{14}$ prospectively reviewed a group of resurfacings performed in patients over the age of 80 years. At a mean of 4.5 years, they had one revision (3.4\%) in a patient with rotator cuff arthropathy (RCA) who was revised to a reverse total shoulder arthroplasty (RTSA).

Al-Hadithy et al. ${ }^{7}$ evaluated 50 patients with osteoarthritis who underwent hemiarthroplasty with humeral resurfacing. At a mean of four years, they had only one revision for a peri-prosthetic fracture.

Contrasting this, Alizadehkhaiyat et al. ${ }^{19}$ followed 102 patients with varying pathologies who had undergone hemiarthroplasty with humeral resurfacing. At a mean of four years, they had revised 13 cases $(12.9 \%)$ in which a standard shell had been inserted, and a further eight cases $(8 \%)$ were awaiting revision. In their study they inserted 11 extended articular surface (EAS) components for RCA, of which six had been, or were awaiting revision.

Revision rates were significantly different between the primary pathologies, with rates of $62.5 \%$ for RCA, $27.5 \%$ for RA, and $10.4 \%$ for OA.

Similar revision rates were encountered when Mechlenburg et al. ${ }^{6}$ retrospectively evaluated 71 patients post humeral resurfacing. At one-year follow-up the Western Ontario Osteoarthritis of the Shoulder Index (WOOS $)^{20}$ score averaged 67 (20-100), and at one- to fiveyear follow-up they had $14 \%$ revisions. Eight of these were for persistent pain which they relate to overstuffing of the joint.

Buchner et al. ${ }^{13}$ prospectively evaluated 22 humeral resurfacings for primary OA. They were seen at six and 12 months post-surgery, and then matched to a comparative group of patients who had undergone TSA. At 12 months the TSA had a tendency towards better absolute CS, but this was not statistically significant. There was a statistically significantly greater improvement in the CS for the TSA over the 12 months, but the baseline preoperative CS of those undergoing TSA was significantly less than those who underwent resurfacing, signifying a degree of selection bias. Of note in the study is two patients $(9 \%)$ in the resurfacing group who were revised within the short 12-month follow-up (at seven and nine months) for persistent pain and glenoid erosion. Although they do not discuss the prosthesis position or size in these two revision cases, they do point out that the pre-operative glenoid was a type B1 (Walch classification of glenoid morphology, ${ }^{21}$ ) and that consideration should be made to implantation of a glenoid component in cases of this configuration.
Although all of the revision cases in the current study were for progressive glenoid erosion and continued pain, the decision on whether to perform a hemi resurfacing, or total shoulder resurfacing is contentious.

The problem of progressive glenoid wear and pain was highlighted by Mansat et al. ${ }^{5}$ who evaluated 64 shoulder hemi-resurfacings. At a mean of 36 months follow-up, the CS reached 68 points (range 29-100). They had five $(8 \%)$ revisions, but emphasised that 20 patients $(31 \%)$ were rated as unsatisfactory on the Neer grading, and 11 $(17 \%)$ shoulders remained painful - related to glenoid erosion in all.

Total shoulder resurfacing has been shown by some to result in improved patient outcomes, but carries with it the associated risk of revision for glenoid component failure. This is highlighted in the study by Levy and Copeland (2001) ${ }^{12}$ when they published their five- to tenyear results with the Mark 2 Copeland prosthesis. Of the 98 shoulder available for review, there were 38 hemiresurfacing and 60 TSA. At a mean of 6.8 years, the best results were seen in those with OA, with adjusted CS of $93.7 \%$ in the TSA group and $73.5 \%$ in the hemi-resurfacing group. There were eight revisions, half of which were related to glenoid component problems.

Contrasting this, other studies show similar functional results for hemi and total resurfacing, and similar revision rates. Pritchett $(2011)^{16}$ prospectively followed 61 patients (74 shoulders) for a minimum of 20 years or till death. They performed 33 hemi-resurfacings and 41 total resurfacings. Excluding those that underwent revision, 95\% were satisfied with their surgery, and 92\% were not limited in their activities. There was no statistically significant difference for function or satisfaction between hemi and total resurfacing. Four of 33 humeral resurfacings were revised (pain or loosening) and three glenoid components required revision.

In an attempt to address this problem, alternative procedures on the glenoid have been employed with varying success. Lee et al..$^{22}$ retrospectively reviewed 21 patients who had undergone humeral resurfacing in combination with biological glenoid resurfacing (utilising the anterior capsule). Two of their patients had been revised - one for infection and one for pain and erosion. Although they found that the interposed tissue did not protect the glenoid from mid-term erosion, they do report high (83\%) patient satisfaction with long-term results, and postulate that the interposed tissue may have delayed the progression of glenoid erosion, and may thereby increase the longevity of the component.

The decision on whether to perform a hemi resurfacing, or total shoulder resurfacing is contentious 


\section{Component positioning}

Humeral resurfacing is reported to centre the implanted prosthesis correctly in terms of version and offset, ${ }^{2}$ and recreate the patients individual anatomy. ${ }^{3}$

Mansat et al..$^{5}$ in their study of 61 Global Cap resurfacings report that the resurfacing reproduces the normal anatomy and compensates for glenohumeral wear, but there was a tendency in their series to insert the prosthesis in relative varus compared to preoperative radiographs $\left(122^{\circ} \pm 1.4^{\circ}\right.$ vs $\left.134^{\circ} \pm 7^{\circ}\right)$ This did not, however, correlate with inferior clinical results.

Similarly, in the current study, although there were differences between surgeons in terms of component inclination - with one of the senior surgeons tending also to insert the prosthesis in relative varus (see surgeon B in Graph 7) - this did not affect the clinical outcomes.

\section{Component offset and version}

In a recent study on the positioning of humeral resurfacings evaluated with computed tomography scans, Deladerriere $e t$ al. ${ }^{4}$ concluded that inclination and lateral gleno-humeral offset were maintained, and medial humeral offset was restored, but there was a tendency to place the prosthesis in insufficient retroversion. They ascribe this to inadequate exposure during surgery.

Although we were not able to measure version in the current study, particular attention was made of any changes to the lateral offset.

Altering the offset has an influence on the function of the rotator cuff and deltoid musculature.

Williams et al. showed in 2001 that restoration of the humeral head-shaft offset to within $4 \mathrm{~mm}$ improved shoulder motion and reduced sub-acromial impingement post TSA. ${ }^{23}$

In order to minimise glenoid erosion, it is suggested that one should not overstuff the joint and that the rotator cuff integrity and the humeral centre of rotation should be restored.

In a biomechanical cadaver study, Hammond et al. ${ }^{24}$ compared resurfacing with third generation stemmed hemiarthroplasty in various functional positions. They found that resurfacing better restored the geometric centre of the humeral head, allowing for improved kinematic behaviour, and postulate that this would minimise eccentric glenoid wear.

Rietveld et $a l .{ }^{25}$, in their study on post-traumatic shoulder arthroplasty, showed that the optimum offset of $26.5 \mathrm{~mm}$ gives the best result in terms of movement (although the contralateral normal shoulder offset averaged $33 \mathrm{~mm}$ ). Thomas et al. ${ }^{2}$ in their resurfacing study, showed that restoring the lever arm is beneficial in terms of functional movement up to a value of about $27 \mathrm{~mm}$; thereafter further increases lead to worse outcomes, possibly representing overstuffing of the joint with its pathologically contracted soft tissues.
Mechlenburg et al. ${ }^{6}$ question the ability of the Copeland resurfacing prosthesis to reproduce the anatomy. In their radiological and clinical outcome study, they report a significantly increased lateral glenohumeral offset post resurfacing $(4.9 \pm 0.53 \mathrm{~cm}$ to $5.39 \pm 0.58 \mathrm{~cm})$ leading to overstuffing of the joint. They attribute this in part to the difference in the amount of proximal humeral reaming $(2 \mathrm{~mm})$ compared to the thickness of the implanted component (average $4 \mathrm{~mm}$ ).

The clinical significance of this was highlighted by AlHadithy et al. ${ }^{7}$ in their series of 50 resurfacings, where 14 cases of mild to moderate glenoid erosion were reported, all of which had oversized components.

In the current study, it is evident that there was a tendency to increase the lateral offset. The mean postoperative offset in the group that was subsequently revised, was $27.5 \mathrm{~mm}$, and in the unrevised group was 29 $\mathrm{mm}$. This finding is in contradiction with what one would expect; however, it must be noted that reasons for revision and poor clinical outcomes are multifactorial and are not limited to radiographic measures. Also, as mentioned before, a number of the radiographs of the revision cases were missing, which led to us being unable to evaluate statistical significance. In the unrevised group, we were unable to demonstrate a clinical difference between cases where the offset was optimally restored and those that were medialised or lateralised.

\section{Results related to diagnosis}

Most studies report optimal results when resurfacing is performed for $\mathrm{OA}$, and relatively poorer results for CTA. ${ }^{12,14}$ CTA in the elderly patient with antero-superior escape and pseudo-paralysis is most predictively managed with reverse total shoulder arthroplasty. There is however a subgroup of patients with CTA who may benefit from hemi-resurfacing: younger patients who are not suitable for RTSA, with pain but reasonably maintained range of motion, and with maintained glenohumeral stability. ${ }^{26}$

The theoretical advantage is ease of revision and improved clinical outcomes when converting a resurfacing to a RTSA; however, this is yet to be clearly determined.

In their study of resurfacing procedures done in rheumatoid patients, Fink et al. ${ }^{27}$ divided their patients into groups depending on the status of the rotator cuff. Group A had an intact cuff, group B a partial or repaired cuff, and group $C$ a large $(>5 \mathrm{~cm})$ tear. In group $C$ they implanted the cup in a valgus position, where it could articulate with the undersurface of the acromion. At 36 months, the mean constant score for the groups was 66.1 for A, 64.9 for B and 56.9 for group C. There was no statistical significant difference in the gain in CS between groups. In group C, they were able to attain limited goal criteria $\left(90^{\circ}\right.$ active forward flexion, no pain, $20^{\circ}$ active external rotation) as per Neer et al..$^{28}$ in all patients. 
In this study, comprising mostly patients with primary osteoarthritis, we could find no correlation between the underlying diagnosis, and the subjective shoulder score post surgery.

\section{Limitations}

There are a number of limitations to this study. It is retrospective, and is reliant on the adequacy and availability of clinical information. There was a paucity of pre-operative shoulder scores to compare post-operative gains. A number of patients were lost to follow-up as they were either not contactable, or their medical records had been lost.

\section{Conclusion}

In this retrospective review of proximal humeral resurfacings, we have evaluated a number of clinical and radiological parameters, and attempted to associate these with clinical outcomes.

We have demonstrated difficulties in correct sizing and component placement as evident by the post-operative radiographic analysis, but were unable to correlate these with clinical scores. We have encountered a wide range of patient-reported shoulder scores and levels of satisfaction which, however unexplainably, have shown better scores for oversized or subjectively poorly positioned prostheses.

Although we have encountered a high revision rate, it is within the range of other published series, and we have noted that revision of resurfacing prostheses to stemmed components is relatively simple, and if necessary, is likely to give a satisfactory clinical result.

Although the surgical technique appears straightforward, technical difficulties in orientation and sizing exist

Proximal humeral resurfacing remains an important part of the shoulder surgeon's armamentarium, and may be of particular benefit when one considers that for any reason, future revision may be necessary. Although the surgical technique appears straightforward, technical difficulties in orientation and sizing exist, and although in this study we have been unable to demonstrate a clinical difference, one should still strive towards anatomic restoration of the proximal humerus.

The authors have no conflicting interests, and have received no benefits for writing this original article.

\section{References}

1. Kim SH, et al. Increasing incidence of shoulder arthroplasty in the United States. I Bone Joint Surg Am, 2011;93(24):2249-54.
2. Thomas SR, et al. Geometrical analysis of Copeland surface replacement shoulder arthroplasty in relation to normal anatomy. J Shoulder Elbow Surg, 2005;14(2):186-92.

3. Levy O, Copeland SA. Cementless surface replacement arthroplasty (Copeland CSRA) for osteoarthritis of the shoulder. J Shoulder Elbow Surg, 2004;13(3):266-71.

4. Deladerriere JY, et al. Geometrical analysis results of 42 resurfacing shoulder prostheses: A CT scan study. Orthop Traumatol Surg Res, 2012;98(5):520-27.

5. Mansat $P$, et al. Resurfacing humeral prosthesis: do we really reconstruct the anatomy? J Shoulder Elbow Surg, 2013;22(5):612-19.

6. Mechlenburg I, et al. The Copeland resurfacing humeral head implant does not restore humeral head anatomy. A retrospective study. Arch Orthop Trauma Surg, 2013;133(5):615-19.

7. Al-Hadithy $\mathrm{N}$, et al. Cementless surface replacement arthroplasty of the shoulder for osteoarthritis: results of fifty Mark III Copeland prosthesis from an independent center with four-year mean follow-up. J Shoulder Elbow Surg, 2012;21(12):1776-81.

8. Dawson J, Fitzpatrick R, Carr A. Questionnaire on the perceptions of patients about shoulder surgery. J Bone Joint Surg Br, 1996;78(4):593-600.

9. Neviaser RJ, Neviaser TJ. Lesions of musculotendinous cuff of shoulder: diagnosis and management. Instr Course Lect, 1981;30:239-57.

10. MacKenzie D. The antero-superior exposure for total shoulder replacement. Orthopaedics and Traumatology, 1993;2:71-77.

11. Clinton J, et al. Nonprosthetic glenoid arthroplasty with humeral hemiarthroplasty and total shoulder arthroplasty yield similar self-assessed outcomes in the management of comparable patients with glenohumeral arthritis. $J$ Shoulder Elbow Surg, 2007;16(5):534-38.

12. Levy O, Copeland SA. Cementless surface replacement arthroplasty of the shoulder. 5- to 10-year results with the Copeland mark-2 prosthesis. J Bone Joint Surg Br, 2001;83(2):213-21.

13. Buchner M, Eschbach N, Loew M. Comparison of the short-term functional results after surface replacement and total shoulder arthroplasty for osteoarthritis of the shoulder: a matched-pair analysis. Arch Orthop Trauma Surg, 2008;128(4):347-54.

14. Mullett $\mathrm{H}$, et al. Copeland surface replacement of the shoulder. Results of an hydroxyapatite-coated cementless implant in patients over 80 years of age. J Bone Joint Surg Br, 2007;89(11):1466-69.

15. Copeland S. The continuing development of shoulder replacement: 'reaching the surface'. J Bone Joint Surg Am, 2006:88(4):900-905.

16. Pritchett JW. Long-term results and patient satisfaction after shoulder resurfacing. I Shoulder Elbow Surg, 2011;20(5):771-77.

17. Constant CR, Murley AH. A clinical method of functional assessment of the shoulder. Clin Orthop Relat Res, 1987;214:160-64.

18. Giannotti S, et al. Shoulder resurfacing with Durom Cup: clinical and radiological re-assessment. J Orthop Sci, 2012;17(5):545-50. 
19. Alizadehkhaiyat $O$, et al. Outcome of Copeland shoulder resurfacing arthroplasty with a 4-year mean follow-up. J Shoulder Elbow Surg, 2013.

20. Lo IK, Griffin S, Kirkley A. The development of a diseasespecific quality of life measurement tool for osteoarthritis of the shoulder: The Western Ontario Osteoarthritis of the Shoulder (WOOS) index. Osteoarthritis Cartilage, 2001;9(8):771-78.

21. Walch $G$, et al. Morphologic study of the glenoid in primary glenohumeral osteoarthritis. J Arthroplasty, 1999;14(6):756-60.

22. Lee KT, Bell S, Salmon J. Cementless surface replacement arthroplasty of the shoulder with biologic resurfacing of the glenoid. J Shoulder Elbow Surg, 2009;18(6):915-19.

23. Williams GR, Jr, et al. The effect of articular malposition after total shoulder arthroplasty on glenohumeral translations, range of motion, and subacromial impingement. J Shoulder Elbow Surg, 2001;10(5):399-409.

24. Hammond G, et al. Biomechanical comparison of anatomic humeral head resurfacing and hemiarthroplasty in functional glenohumeral positions. J Bone Joint Surg Am, 2012;94(1):68-76.
25. Rietveld $\mathrm{AB}$, et al. The lever arm in glenohumeral abduction after hemiarthroplasty. J Bone Joint Surg Br, 1988;70(4):561-65.

26. Pape $G$, et al. Treatment of severe cuff tear arthropathy with the humeral head resurfacing arthroplasty: two-year minimum follow-up. J Shoulder Elbow Surg, 2013;22(1):e17.

27. Fink B, et al. Surface replacement of the humeral head in rheumatoid arthritis. Arch Orthop Trauma Surg, 2004;124(6):366-73.

28. Neer CS, 2nd, Watson KC, Stanton FJ. Recent experience in total shoulder replacement. J Bone Joint Surg Am, 1982;64(3):319-37.

This article is also available online on the SAOA website (www.saoa.org.za) and the SciELO website (www.scielo.org.za). Follow the directions on the Contents page of this journal to access it. 